\title{
ACTION REGULATION INTRODUCING STRESS MANAGEMENT TECHNIQUES AND HIGH PERFORMANCE IN SOCCER
}

\author{
Dr. Soumendra Saha, Dr. Srilekha Saha and Nurfarah Ezzaty Binti Mohd Zahir \\ Exercise \& Sports Sciences Programme. School of Health Sciences, PPSK \\ Universiti Sains Malaysia Kota Bharu, Kelantan, Malaysia.16150. \\ author email: drsoumen@kk.usm.my
}

\section{ABSTRACT}

Fifty-two high performing soccer players of South-East Asian contingent were selected by three expert soccer instructors on the basis of their consistent high performance and on the basis of their performance on psychomotor and psychobiological parameters. All of these players were subjected to pre-intervention analyses of Sc orienting reflex indices (phasic components of electrodermal activity) as well as sympathovagal activity based on HRV indices which were assessed simultaneously while the players were engaged in psychomotor reaction ability performances. Structural equations were done to identify the path regression related to performance excellence, which were suggestive of incoherence between the predictors. Short-term intensive self-regulation as well as action-regulation training modules was developed to foster ideomotor orientation in the players, which however was found effective in modification of the intrinsic psychobiological mechanism leading towards excellence in performance in the high-performer soccer players. Thus they were randomly categorised into four groups, comprising of one no-intervention control group $(N=13)$; experimental group I $(N=13)$ who received action-regulation training; experimental group $\|(N=13)$, who received training of electromyography (EMG) biofeedback, and experimental group III $(N=13)$, who received combined training of action - regulation and electromyography (EMG) biofeedback (for $15 \mathrm{~min} . \mathrm{s} / \mathrm{day}$, for 3 days per week, for 12 weeks). Repeated measure of ANOVA and multiple linear and polynomial regression analyses along with the predictive structural analyses were done to identify relationships between the psychobiological processes, in relation to the cognitive-affective and affective-motivational aspects of sports behaviour, revealed by the projective analyses of emotionality. These models were aptly able to explain the efficacy of the action-regulation intervention techniques, in inducing the cognitive flexibility and emotional resilience required for performance excellence in elite-level soccer players.

Key Words: Action -regulation; EMG Biofeedback; High Performance; Soccer

\section{INTRODUCTION}

Intense work-pressure, sky-rising self-aspiration and demands from the keens and intimates put almost all of us into a predicament to perceive extreme level of over-whelming stress in day-to-day life. Modern developments in cutting-edge technology, outstanding improvement in communication actually put forth us into tormenting experiences. Contrary to that, endless provocations from our surroundings result in an incompetent yet ardent desire to achieve success, which invariably put most of us into a point of no return. Available dearth of literatures have pointed out that, children as well as young-adult individuals with emotional problems often are raised in families where disturbed and pathogenic family affairs; work-pressure; strained relationships, make them emotionally vulnerable to become insecure and anxious (Biswas et al. 1998). Previous researches done by the authors of the present study also evidenced prevalence of heightened emotionality, inattentiveness in majority of the 
urban families characterized by the nuclear formation of the families (Biswas et al. 1998; Saha et al. 1998).

At this outset, prior to get concerned about how to handle the over-whelming emotional crises, what should be the coping strategies, it seems significant to realize the characteristics of the emotional overloading and the nature of cognitive-motivational crises involved in it. First of all we need to ascertain with regard to the validity and relevance of the evaluation of emotional crises. Researchers in the field of stress have been observed either to pay attention to only self-report subjective evaluation of feelings of stress, tension and anxiety, or to concentrate onto the physiological evaluations identical to electrocardiography or electroencephalography only. Neither of these separately can ensure valid and confirmed evaluation of the extent of deep-seated anxiety, which may have numerous severe social consequences. In psychology, projective evaluations are content analyzed and hence are considered as most potent and valid method in revealing hidden emotions and internal conflicts (Cordon, 2005). These tests must be used following rigorous methodology; otherwise scientific evidence may sometimes become debated.

The skin conductance $(\mathrm{Sc})$ measure on the other hand is a technique commonly used to assess autonomic indices of emotionality from the volar surface of the skin in response to the eccrine sweat gland function. Any stimulus capable of creating autonomic arousal can evoke the response and the amplitude of the response is more dependent on the startling effect of the stimulus than on the physical stimulus strength. Sc studies in sport science researches have usually paid attention to tonic Sc only, while only phasic Sc evaluations done in habituation paradigm, comprising of components like amplitude, latency and recovery time etc. would reveal inner psychological and psychobiological constraints related to performance (Dawson et al. 2000; Lim et al. 1997; Bendeck \& Karenbach, 2010; and Saha et al, $2005 \& 2012 a)$.

Now the question could be as to why do we need to concentrate on optimal evaluation of deeprooted emotionality? For quite a few decades, it has been suggested that apart from playing conditions and physical conditioning and playing strategies, lot many potential confounding factors may interact behind athletic performance. One of the integral contributors of athletic excellence is dependent on his or her mental toughness or more specifically the aspect of emotional flexibility and hardiness. Projective evaluations of emotionality can reveal hidden emotional crises and internal conflicts and similarly psychobiological evaluations can serve as emotional indices and can provide us with corroborative objective as well as valid etiological information. Furthermore, the advantage of relying on both of the measures (viz., projective and psychobiological autonomic evaluation) would be that outcomes of evaluations cannot be subjective and cannot be manipulated and hence if evaluated following rigorous methodology and the data are interpreted by the experts with adequate care and attention, these measures can provide with vital information concerning cognitive-emotional processes underlying and behaviour pathology occurring in the field of sports. Further to add, this would also be helpful in evaluation of biofeedback trainings in modulating dispositional as well as transient emotional crises. With such a background, we wanted to investigate into the substantiated relationship between psychobiological components and projective evaluation of emotionality to examine the aspects phasic skin conductance component in young adolescent players;

a) To identify the relationship between the skin conductance orienting amplitude indices and corroborative projective analysis of emotionality if any, amongst the young adult competitive soccer players ;

b) To investigate the efficacy of the electromyography biofeedback training in modulating stress-dependent performance disruptions; 
c) To justify the impact of introduction of action regulation intervention training in the soccer players in improvement of their performance.

\section{METHOD}

Participants

Fifty-two young-adult male competitive soccer players (age-raged 19.6 to 23.4 years; Mean = 22.1 yr.s \& 1.66) of Kota Bharu region in Malaysia rated by their respective coaches as consistently high performing players, volunteered as participants. Thus they were randomly categorized into four groups, comprising of one no-intervention control group $(\mathrm{N}=13)$; experimental group I $(\mathrm{N}=$ 13) who received action-regulation training; experimental group II $(N=13)$, who received training of electromyography (EMG) biofeedback, and experimental group III $(N=13)$, who received combined training of action - regulation and electromyography (EMG) biofeedback (for $15 \mathrm{~min} . \mathrm{s} /$ day, for 3 days per week, for 12 weeks).

Total number of samples was calculated by employing statistical tool G power 3.1.7 (Faul et al. 2013), and the calculation protocol is represented herewith:

[1] -- Saturday, March 29, 2014 -- 08:32:40

F tests - ANOVA: Repeated measures, within-between interaction

Analysis: A priori: Compute required sample size

Input:

Effect size $f$

$=0.25$

a err prob

$=0.05$

Power (1- $\beta$ err prob)

$=0.95$

Number of groups

$=4$

Number of measurements

$=4$

Corr among rep measures

$=0.5$

Nonsphericity correction $\varepsilon \quad=1$

Output: $\quad$ Noncentrality parameter $\lambda$

$=26.0000000$

Critical $F$

$=1.9454502$

Numerator df

$=9.0000000$

Denominator df

$=144$

Total sample size

$=52$

Actual power

Materials and measures -

$=0.9583640$

1. Skin Conductance apparatus (ProComp5 Infinity, USA 2014 represented in Fig. 1) was used to assess the extents of tonic and phasic autonomic regulation, orienting skin conductance recovery response as index of optimal emotional regulation in the soccer players.

2. Electromyography assessment and biofeedback apparatus (Mega ME 6000 , USA 2009 represented in Fog. 2) was used to assess the extents of muscular fatigue; maximal voluntary contraction and Mean power frequency observed in the participants.

3. Rorschach Ink blot-test (RIB) was administered to evaluate inner emotional core components of the soccer players.

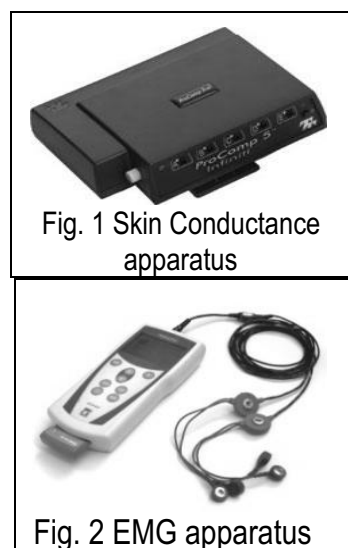

Fig. 2 EMG apparatus 


\section{PROCEDURE}

For the purpose of this present study emotionality was evaluated by introduction of projective test by employing Rorschach Ink-blot (RIB) test. Fig. 3 represents the types of Rorschach Ink-blots cards are universally used to identify inherent hidden emotionality. On the basis of the scores obtained from the projective analyses of emotionality (employing RIB), emotional measures of enthusiasm; emotional flexibility; integrity; impulsivity; motor control; irritability; self-esteem; somatization; pleasant affect and suspicion were derived. For all of the psychobiological analyses Skin conductance tonic and phasic autonomic regulation and orienting skin conductance activity - i.e., Sc response amplitude measures related to emotional behaviour was evaluated. Tonic and phasic Sc (Sc) activity data were further decomposed as basal or tonic Sc; SF or NS-SCR (non-specific Sc response, which is also termed as spontaneous fluctuation or SF) and

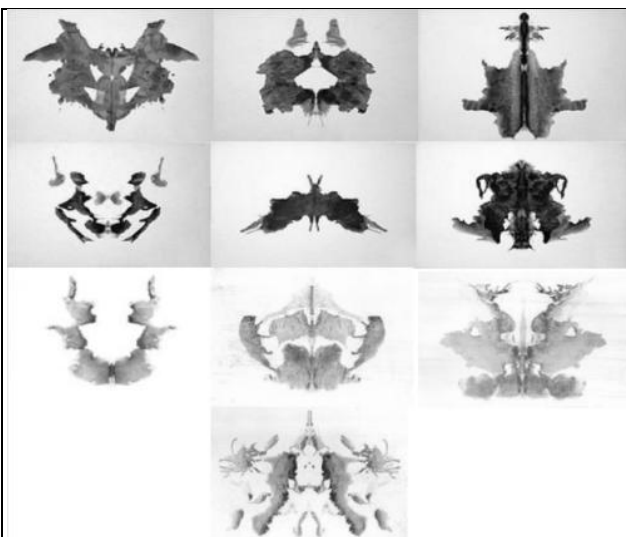

Fig. 3 Projective emotionality was evaluated by employing Rorschach Ink-blot test

tonic consistency measures; and, phasic Sc, and stimulus-specific orienting response measures (viz. latency; amplitude and recovery time). Here we would also need to clarify our position with the fact that, majority of the players were observed to have considerably sharper amplitude and faster recovery time. Information based on inner core emotionality was investigated on the basis of their other psychological as well as concomitant psychobiological attributes.

Electromyography analyses were done employing ME6000 telemetric or ambulatory evaluation systems, in which the apparatus incorporates automated gain adjustment throughout a dynamic range of 10 to $1500 \mathrm{gV}$. Bandpass filtering was carried out prior to the root mean square (rms) conversion. The bandwidth used was $100 \mathrm{~Hz}$ to $540 \mathrm{~Hz}$ with a $60-\mathrm{Hz}$ notch filter. The filtered integrated signal was averaged bi- laterally and digitally stored for each 10-second contraction period. For all of the aforementioned analyses, participants were assessed in the laboratory of sports science at the School of Health Science, in the Universiti Sains Malaysia (orienting skin conductance responses were recorded at the resting heart-rate level - methodology detailed in the Saha et al. 2012a).

After the pre-intervention or baseline assessment, participants were randomly categorized into four groups, comprising of one no-intervention control group ( $N=13)$; experimental group I $(N=13)$ who received actionregulation training (see Fig. 5 as an example of action regulation training); experimental group II $(\mathrm{N}=13)$, who received training of electromyography (EMG) biofeedback, and experimental group III $(\mathrm{N}=13)$, who received combined training of action - regulation and electromyography (EMG) biofeedback. Intervention protocol was kept constant for all of the interventions viz., 15 min.s/day, 3 days per wk., 12 weeks. Mid-term analyses were conducted after the $6^{\text {th }}$ week of intervention. Thereafter at the end of the intervention of the $12^{\text {th }}$ week, all of the players were finally assessed with all of the afore-mentioned parameters for the postintervention analyses.

Data were treated with SPSS 20.0 for identification of the normality index. Thereafter multiple linear regression analyses were done to identify how far the different psychobiological variables (obtained from Sc measures) and psychological (emotional flexibility and integrity phenomena)

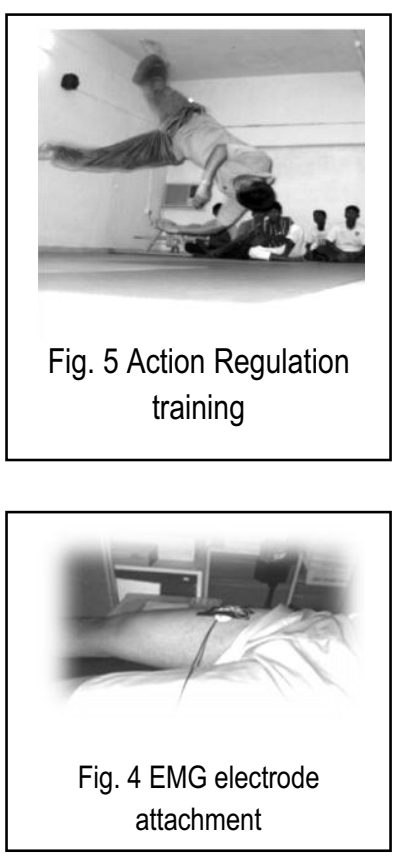


contribute in the shared aetiology of consistency in excellent performance in sports. Repeated measure of ANOVA was done to identify whether differential interventions had any beneficial impacts or not.

\section{RESULTS}

Descriptive analyses were done on the data obtained from all of the participants especially to evaluate the normality index, and for that measures of central tendency and variability were done along with measures of skewness and kurtosis. Descriptive reports however showed that data were more or less consistent and were at par with the normality index, and wherever minor discrepancies were observed measures for correction were taken up. Table 1 represents the nature of descriptive data relative to projective analyses of emotionality.

Table 1 - Descriptive measures of projective evaluation of emotion related variables obtained from the participants (represented the normality index of the whole sample)

\begin{tabular}{|c|c|c|c|c|c|c|c|c|c|c|}
\hline 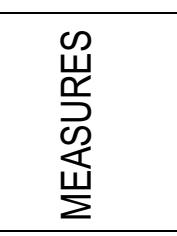 & 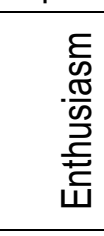 & 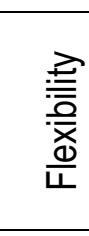 & 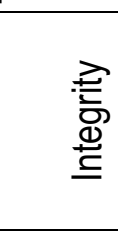 & 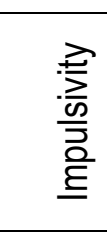 & $\begin{array}{l}\overline{0} \\
\text { 응 } \\
0 \\
\text { 흠 } \\
\text { 을 }\end{array}$ & 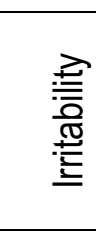 & 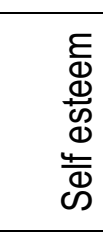 & 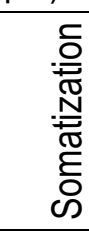 & 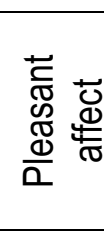 & $\begin{array}{l}\text { 등 } \\
\text { 음 } \\
\text { के } \\
\text { क }\end{array}$ \\
\hline Mean & 19.8 & 4.58 & 13.81 & 5.86 & 3.28 & 2.49 & 1.76 & 2.85 & 52.78 & 5.97 \\
\hline SD & 6.28 & 1.45 & 3.45 & 2.10 & 1.03 & .91 & .61 & .45 & 12.02 & 2.01 \\
\hline Skewness & -.300 & .935 & .234 & .427 & 1.003 & .684 & .166 & 1.11 & .255 & -.335 \\
\hline Kurtosis & -.535 & .413 & -.185 & -.566 & .742 & .198 & -.663 & .595 & .641 & -.926 \\
\hline
\end{tabular}

Table 2 - Multiple Linear Regression Representing Emotional Factors as Predictors for the Participants of Experimental Group I

\begin{tabular}{|c|c|c|c|c|c|c|c|}
\hline \multirow{2}{*}{$\begin{array}{c}\text { Dep. Variable - } \\
\text { Skin } \\
\text { Conductance } \\
\text { Amplitude }\end{array}$} & \multicolumn{2}{|c|}{$\begin{array}{l}\text { Unstandardized } \\
\text { Coefficients }\end{array}$} & \multirow{2}{*}{\begin{tabular}{|c|}
$\begin{array}{c}\text { Standardized } \\
\text { Coefficients }\end{array}$ \\
Beta \\
\end{tabular}} & \multirow[b]{2}{*}{$\mathrm{t}$} & \multirow[b]{2}{*}{ Sig. } & \multicolumn{2}{|c|}{$95.0 \%$ Confidence Interval for $\mathrm{B}$} \\
\hline & B & Std. Error & & & & Lower Bound & Upper Bound \\
\hline (Constant) & 3.96 & 4.17 & & .95 & .361 & -4.38 & 12.31 \\
\hline Flexibility & -1.42 & .46 & -.34 & -3.09 & .001 & -2.256 & -.50 \\
\hline Impulsivity & 1.55 & .41 & .36 & 3.78 & .000 & .73 & 2.762 \\
\hline Self-esteem & -1.94 & .44 & -.36 & -4.41 & .000 & -2.82 & -1.06 \\
\hline Somatization & .48 & 26 & .15 & 1.85 & .095 & -.04 & 1.01 \\
\hline Pleasant affect & -.09 & .04 & -.16 & -2.19 & .031 & -.17 & -.01 \\
\hline Suspicion & .62 & .29 & .18 & 2.15 & .034 & .05 & 1.18 \\
\hline
\end{tabular}

$\mathrm{a}(\mathrm{F}(2,11)=7.56, \mathrm{P}<0.000))$ Model Adj. $\mathrm{R}^{2}=73.6 \%$

Table 3 - Multiple Linear Regression Representing Emotional Factors as Predictors for the Participants of Experimental Group II

\begin{tabular}{|c|c|c|c|c|c|c|c|}
\hline \multirow{2}{*}{$\begin{array}{l}\text { Dep. Variable - } \\
\text { EMG Recovery }\end{array}$} & \multicolumn{2}{|c|}{$\begin{array}{l}\text { Unstandardized } \\
\text { Coefficients }\end{array}$} & \multirow{2}{*}{\begin{tabular}{|c|}
$\begin{array}{c}\text { Standardized } \\
\text { Coefficients }\end{array}$ \\
Beta \\
\end{tabular}} & \multirow[b]{2}{*}{$t$} & \multirow[b]{2}{*}{ Sig. } & \multicolumn{2}{|c|}{$\begin{array}{l}\text { 95.0\% Confidence Interval for } \\
\text { B }\end{array}$} \\
\hline & $\mathrm{B}$ & Std. Error & & & & Lower Bound & Upper Bound \\
\hline Intercept & 86.93 & 11.05 & & 10.090 & .000 & 58.978 & 99.817 \\
\hline Self-esteem & -6.12 & .37 & -1.29 & -16.54 & .000 & -6.86 & -5.38 \\
\hline Somatization & -.59 & 28 & -.17 & -2.10 & .020 & -1.15 & -.03 \\
\hline Pleasant affect & -.07 & .02 & -.14 & -3.5 & .001 & -.11 & -.03 \\
\hline Suspicion & 1.59 & .18 & .47 & 8.83 & .000 & 1.23 & 1.95 \\
\hline
\end{tabular}

$\mathrm{b}(\mathrm{F}(1,11)=9.51, \mathrm{P}<0.000))$ Model Adj. $\mathrm{R}^{2}=81.9 \%$. 
Result tables 2 and 3, however explained the relationships existing between different parameters measured. Multiple linear regression analyses were done to identify predictive associations between the psychophysiological as well as projective analyses of emotionality. In the Table 2, the model a however explained that, the model emerged significant as the projective components of emotionality could explain $73.6 \%$ variance of changes in the extent of skin conductance amplitude in the players who received action-regulation intervention. Similarly Table 3 reports implied that the model $b$ emerged significant since the independent predictors of inherent emotionality could explain as high as $81.9 \%$ of extent of variance changes in autonomic recovery from fatigue observed in the players of group II, as could be revealed by the EMG analyses.

Table 4 - Multiple Linear Regression Representing Emotional Factors as Predictors for the Participants of Experimental Group III

\begin{tabular}{|c|c|c|c|c|c|c|c|}
\hline \multirow{2}{*}{$\begin{array}{c}\text { Dep. Variable - } \\
\text { Skin Conductance } \\
\text { Amplitude }\end{array}$} & \multicolumn{2}{|c|}{$\begin{array}{l}\text { Unstandardized } \\
\text { Coefficients }\end{array}$} & \multirow{2}{*}{\begin{tabular}{|c|}
$\begin{array}{c}\text { Standardized } \\
\text { Coefficients }\end{array}$ \\
Beta
\end{tabular}} & \multirow[b]{2}{*}{$\mathrm{t}$} & \multicolumn{3}{|c|}{$\begin{array}{l}95.0 \% \text { Confidence Interval for } \\
\text { B }\end{array}$} \\
\hline & $\mathrm{B}$ & Std. Error & & & Sig. & Lower Bound & Upper Bound \\
\hline Intercept & 67.35 & 9.05 & & 10.090 & .000 & 58.978 & 99.817 \\
\hline Impulsivity & 4.68 & .32 & .96 & 14.63 & .000 & 4.04 & 5.32 \\
\hline |rritability & -3.20 & 30 & -.74 & -10.67 & .000 & -3.80 & -2.60 \\
\hline Self-esteem & -6.12 & .37 & -1.29 & -16.54 & .000 & -6.86 & -5.38 \\
\hline Somatization & -.59 & 28 & -.17 & -2.10 & .020 & -1.15 & -.03 \\
\hline Pleasant aff & -.07 & .02 & -.14 & -3.5 & .001 & -.11 & -.03 \\
\hline Suspicion & 1.59 & 18 & 47 & 8.83 & .000 & 1.23 & 1.95 \\
\hline
\end{tabular}
$\left.{ }^{c}(\mathrm{~F}(3,10)=8.84, \mathrm{P}<0.000)\right)$ Model Adj. $\mathrm{R}^{2}=75.2 \%$.

Result table 4 depicted that the players who received combined training of action-regulation intervention and EMG biofeedback, could benefit from the interventions as the predictive associations between the Sc amplitude and parameters of projective analyses of emotionality were established. In the Table 4, the model $c$ however explained that, the model emerged significant as the projective components of emotionality could explain $75.2 \%$ variance of changes in the extent of skin conductance amplitude. 


\section{DISCUSSION}

Findings summarized in the table 1 depicted that the data from the projective evaluation of emotionality appeared more or less consistent and those are at par with the normality index. Outcomes of the prediction analysis however are presented in the Tables 2, $3 \& 4$, which however suggested that the emotionality in the participants indexed from the psychobiological autonomic indices and from the inner unconscious core (as it was derived by employing the Rorschach Inkblot test) were found adequately substantiated. Furthermore, the psychobiological autonomic indices were found closely associated with those of emotionality measures obtained from projective analyses. Rorschach index scores provided information with regard to corroborative inner unconscious emotional core contents, which have given us opportunity to optimize the correlated emotional aspects, viz. extent of emotional flexibility; integrity; impulsivity; motor control; irritability; self-esteem; somatization; pleasant affect and suspicion. Predictive structural equation derived from path regression analyses were already suggestive of interrelationships (Saha et al. 2013d), which were further evident in the automatic linear models (refer to fig. 6). Coefficients for estimation of regression however suggested an overall explanation in terms of both linear and multiple linear influence of these variables on the emotionality of the participants, which were found on line

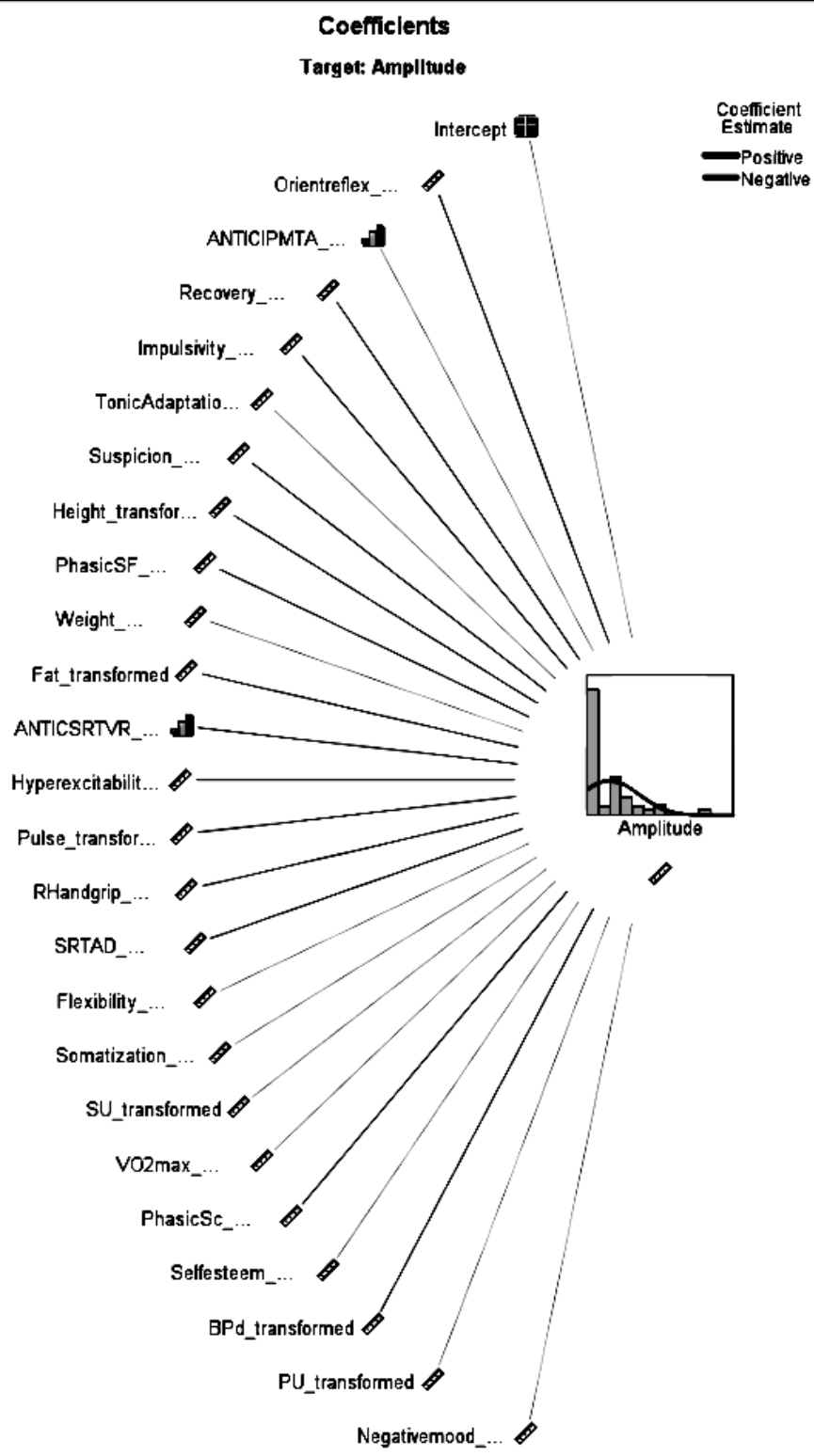

Fig 6. Relationship between autonomic response amplitude and other factors of emotionality; health and fitness parameters. with findings of previous studies following similar methodology (Saha et al. 2013a; 2013b \& 2013d).

Our previous researches also confirmed that the adaptive emotionality is one of the most integral aspects of skilful sport performance (Saha et al. 2012a, b \& c). Hence, the cognitive-emotion related components and the psychobiological components of emotional regulation and the consequent behavioural component and the final goal-directed emotional behaviour were transformed into some cognitive-emotional constellations (viz., emotional flexibility; integrity; self-esteem as well as suspicion). These transformations being aptly related to other perceptual, cognitive and emotional aspects, either separately or in multiple combined interactional ways as well developed predictive behaviour trajectory (Heyman 1982 and Tenenbaum et al 1992). 
Here we would be interested to pay detailed attention to the reports on the obtained regression coefficients which would more comprehensively explain this phenomenon in emotional perspectives. Model a (Table 2) however explained the outcomes of multiple linear regression analysis, which emerged significant as the predictors - such as extent of emotional flexibility; impulsivity; self-esteem; somatization; pleasant affect and suspicion together could explain $73.6 \%$ of variance changes in the extent of skin conductance amplitude. This model specifically clarified that the players who got themselves trained in action-regulation intervention, had negative as well as positive associations between cognitive-emotional aspects and the extent of Sc amplitude. Interestingly enough the direct relationships revealed that players with lesser extent of impulsivity and lower extent of suspiciousness had higher amplitude. Similarly, higher extent of sense of pleasantness; high self-esteem and higher extent of emotional flexibility together could facilitate in having higher autonomic competence (in the form of high Sc orienting amplitude). Previous research reports from similar research endeavours revealed that, players having relatively lesser extent of orienting latency (that means those had faster autonomic response latency) were observed to have higher emotional resilience (Saha et al. 2005; 2012a \& 2012b, 2013a). Thus the regression analysis revealed a shared and substantiated contribution of psychobiological index and deep-rooted inner core cognitive-emotional constellations, which is found on line with the finding of Saha et al (2013d) and Singer (1988).

Now the question may arise with regard to how far the inner core feelings of emotionality observed in the players could influence in facilitating autonomic competence. Model $\boldsymbol{b}$ explained this relationship as it emerged significant, and the predictors - such as extent of enthusiasm; emotional flexibility; integrity; impulsivity; motor control; irritability; self-esteem; somatization; pleasant affect and suspicion together could explain $81.9 \%$ of variance changes in the extent of EMG recovery from fatigue, observed in the players who received EMG biofeedback training. Alike in the model a here too, both negative as well as positive associations between cognitive-emotional aspects were observed in relation to the extent of autonomic response amplitude. Positive relationships were observed between amplitude and emotional factors such as, enthusiasm; impulsivity and suspicion, while emotional flexibility; integrity; motor control; irritability; self-esteem; somatization and pleasant affect were observed as negatively associated with orienting amplitude. Here before clarifying the afore-mentioned relationships, we need to admit that, very complicated relationships between autonomic response amplitude and emotional constellations have been observed. This should be the characteristic feature of the autonomic amplitude, as well as in the recovery from autonomic or peripheral neural tension, since arousal could be resulted from both negative and positive emotions as well as from facilitative and negative emotional changes too (Dawson et al. 2000; Saha et al. 2005; 2012a \& b). 
Now let us concentrate onto the outcomes of the repeated measure of ANOVA (Table 5), which however revealed that as the emotional stability indices progressed players were observed to have higher extent of autonomic competence (revealed through higher Sc amplitude responses), and better recovery from muscle-potential fatigability (with introduction of EMG biofeedback training). These outcomes further revealed that training of action regulation as well as EMG biofeedback were effective enough to produce changes in the level of emotional stability, which however were found associated with autonomic competence and muscle potentiality too.

Model

c relationships however revealed that, majority of the players who got training of combined intervention of action regulation and EMG biofeedback, were observed to have high extent of Sc amplitude, which is considered as characteristic feature of high performing players and athletes (Lim et al. 2010; Dawson et al. 2000 and Saha et al. 2012 a \& b). Now, this high autonomic response amplitude was evidentially substantiated by the emotional

\begin{tabular}{|c|c|c|c|c|}
\hline \multicolumn{5}{|c|}{$\begin{array}{l}\text { Table 5 Estimated Marginal Means (Cotained from } \\
\text { 1. Projective Emotionaling }\end{array}$} \\
\hline Proiective & Mean & Sto. Error & \multicolumn{2}{|c|}{ 95\% Confoence interval } \\
\hline$\frac{1}{6}$ & \begin{tabular}{r|}
10.374 \\
17.546 \\
.936 \\
\end{tabular} & $\begin{array}{r}1.038 \\
.589 \\
.099\end{array}$ & \begin{tabular}{r|}
8.843 \\
15.765 \\
.294 \\
\end{tabular} & $\begin{array}{r}13.225 \\
17.768 \\
.699 \\
\end{array}$ \\
\hline \multicolumn{5}{|c|}{$\begin{array}{l}\text { The levels of projective emotionality are labelled simply as } 1,2 \text { and } 3 \text {, } \\
\text { which has referred o as stable, moderately stable and disnptive } \\
\text { emotionality, and the table of means reflected that very low exaent of } \\
\text { scores were evident as disnotive emotionality compared to maximum } \\
\text { humbers of mocerately stable emotionality followed by substantial extent } \\
\text { of stable emotionality indices. }\end{array}$} \\
\hline
\end{tabular}

2. Skin Conductance Amplituce

\begin{tabular}{|l|r|r|r|r|}
\hline \begin{tabular}{|l|r|r|} 
Skin \\
Conductance \\
Amplitude
\end{tabular} & Mean & Std. Error & \multicolumn{2}{|c|}{ S5\% Conficence Interval } \\
\hline 1 & & & Lower Bound & Upper Bound \\
\hline$\beta$ & 1.950 & .107 & 1.730 & 2.169 \\
$\beta$ & 7.385 & .701 & 5.944 & 8.822 \\
\hline
\end{tabular}

The levels of amplitude are labelled simply as 1,2 and 3, which has referred to as short, moderane and high amplitude, and the table of means refiected that very iew autonomic amoltudes were short followed oy mone moderate compared with maximum numbers of high amplinjde response incices.

\section{EMG Recoven}

\begin{tabular}{|l|r|r|r|r|}
\hline EMG & Mean & Sto. Error & \multicolumn{2}{|c|}{ 95\% confdence interval } \\
\cline { 4 - 5 } Recovery & & & Lower Bound & Upper Bound \\
\hline 1 & 8.591 & .375 & 7.821 & 9.361 \\
$k$ & 9.491 & .502 & 8.460 & 10.522 \\
\hline 3 & 10.213 & .510 & 9.166 & 11.260 \\
\hline
\end{tabular}

The leves of EMG recovery are labeled simply as 1,2 and 3, which has referred to as taster, delayed and very delayed recovery trom fatigue revealed or EMG analyses. and the table of means reflected anat peripheral neuronal recovery scores were evenly distributed across the responses cotained.

Table 5 representing outcomes of repeated measure of ANOVA components in different ways since, enthusiasm; impulsivity and suspicion were observed to have direct relationship, while emotional flexibility; integrity; motor control; irritability; self-esteem; somatization and pleasant affect were observed as negatively associated with autonomic amplitude. Here it could be acknowledged that, athletes having high amplitude obviously would have high 
enthusiasm and lower somatised anxiety which prompted in low-level of irritability. These relationships between inner core emotionality and concomitant psychobiological changes could be explained as influenced by ipsilateral control from the hypothalamus and limbic system (Sequeira and Roy, 1993),

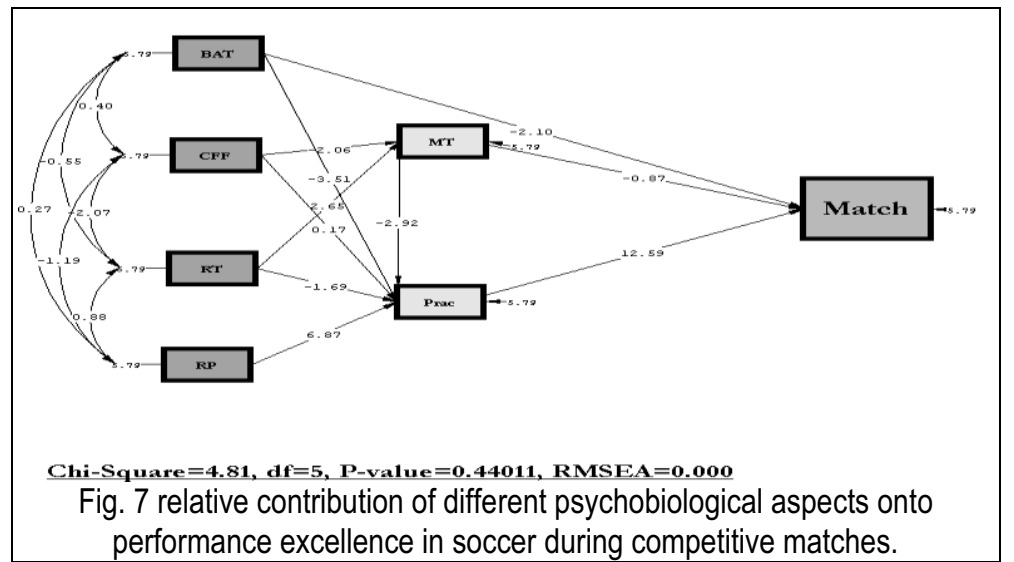
and skin conductance response amplitude is the indicator for the excitatory hypothalamic control mediated through amygdala (Dawson et al. 2000). Here the questions arise with the diverse role of limbic influences, which are definitely complicated, since alike the excitatory hypothalamic control, simultaneous inhibitory influence originating from the hippocampus also occur. That could be the reason behind the complicated scenario observed with the players and athletes, who had high response amplitude, which was found associated with the lower level of pleasant affect; low emphasis on motor control, but a high extent of impulsivity and high sense of suspicion as well as lower extent of self-esteem; flexibility and integrity. These diverse relationships signify the complex nature of cognitiveemotional constellation substantiated by the high autonomic response amplitude, which would be considered as the hypothetical relationships proposed in Beauchaine's (2001) BIS (Behaviour-Inhibition System). Fig. 7 however depicted structural relationships between the psychobiological and pther psychological aspects which finally contributed in improvement in match performances observed in the players. While subjective feeling of lower level of pleasant affect; low emphasis on motor control, as well as lower extent of self-esteem would stem out of introversion tendencies of being predominantly concerned with one's own mental life (Helgoe, 2008); but a high extent of impulsivity and high sense of suspicion as well as evidential lacks in emotional flexibility and integrity would be characteristic feature of maladaptive or neurotic tendencies (Beauchaine, 2001). These all being complex cognitive-emotional constellation would be susceptible to result in high autonomic startling response amplitude (which is actually a stable autonomic characteristic index of emotionality), which might have been mediated through prefrontal cortical activity associated with orienting behaviour and the contralateral cortical and basal ganglion influences (Sequeira \& Roy, 1993) mediating excitatory control by premotor cortex and both excitatory and inhibitory influences originating in the prefrontal cortex (Dawson et al. 2000). Obtained relationships in this model have particular significance as adequate association between relatively higher extent of autonomic orienting response amplitude (which reveals higher level of autonomic reaction to startling situations) and several components of cognitive-emotional constellations have been found substantiated, which have been found adequately supported by the findings of Edelberg (1993); Levenson (1992) and Saha et al. (2012a). Findings however proposed that owing to cognitive-emotional variations the athletes might be susceptible to have higher extent of startling autonomic amplitude but majority of them were also found to have better ability to cope with the emotional crises and that was found substantiated by the evident faster recovery ratio. Thus inner core emotionality identified with the projective measure of emotionality was found consistently substantiated by the explanatory psychobiological index of emotionality. 


\section{CONCLUSION}

1) Higher extent of autonomic competence was found contributed by higher self-esteem, pleasant affect and high level of emotional flexibility.

2) EMG biofeedback training was found to facilitate in reduction of muscular fatigability, which was more obvious in the players who had relatively lower self-esteem; somatization crises; lower extent of pleasantness and relatively higher extent of suspicious feelings.

3) Action regulation training was found to facilitate in autonomic competence, which was associated with changes in impulsivity and irritability as well as in suspicion and in self-esteem of the players.

\section{REFERENCES}

Beauchaine, T. (2001). Vagal tone, development, and Gray's motivational theory: Toward an integrated model of autonomic nervous system functioning in psychopathology. Development and Psychopathology, 13, pp 183-214.

Bendeck, M. \& Karenbach, C. (2010). Decomposition of skin conductance data by means of non-negative deconvolution. Psychophysiology, 47, pp 647-658. Wiley Periodicals, Inc. Printed in the USA.

Biswas, D.; Saha, S; Chattopadhyay, P.K., and Saha, S. (1998). Exercise as an aid to social and emotional adjustment in children: Role of swimming. Journal of Physical Education and Sports Sciences, 1\&2, 13-19.

Cordón, Luis A. (2005). Popular psychology: an encyclopedia. Westport, Conn: Greenwood Press. pp. 201-204.

Dawson, M. E., Schell, A. M., \& Filion, D. L. (2000). The Electrodermal System. In Cacioppo J. T., Tassinary L. G. \& Berntson G. G. (Eds.) Handbook of Psychophysiology, 2nd Ed. New York, Cambridge University Press.

Edelberg, R. (1993). Electrodermal mechanisms: A critique of the two-factor hypothesis and a proposed replacement. In Roy et al., pp. 7 -29.

Helgoe, L. (2008). "Introvert Power: Why Your Inner Life is Your Hidden Strength". Naperville, Illinois: Sourcebooks, Inc.

Levenson, R. W. (1992). Autonomic nervous system differences among emotions. Psychological Science, 3, pp $23-27$.

Lim, C. L., Rennie, C., Barry, R. J., Bahramali, H., Lazzaro, I, Manor, B. \& Gordon, E. (1997). Decomposing skin conductance into tonic and phasic components. International Journal of Psychophysiology, 25, pp 97-109.

Rorschach, Herman. (1942). Psychodiagnostics. (English translation of Psychodiagnostik.) N. Y., Grune \& Stratton.

Saha, S; Biswas, D.; Chattopadhyay, P. K., and Saha, S. (1998). Family size and emotional adjustment in children. Social Science International, 14: 1\&2, pp 35-40.

Saha S., Mukhopadhyay Pritha, Chattopadhyay P. K., Biswas D., \& Saha S. (2005). Arousal modulation as predictor of achievement motivation in high soccer performers. Reading in Sports Psychology. Jitendra Mohon and Meena Sehgal (Eds.) Friends Publications, India, pp 116-146.

Saha, S., Saha Srilekha and Chowdhury, D. (2013). Predictors of autonomic orienting activity as precursor of poor performance in cricket. In the proceeding of Asia- Pacific International Conference on Sports and Exercise Psychology, pp $15-21$.

Saha, S., Saha Srilekha; Chowdhury, D.; Fahim N. A \& Salah Uddin M. (2012a). In search of predictors for reaction ability related to high performance in Cricket. Social Science International, 28 (1), pp $1-18$. 
Saha, S., Saha Srilekha; Chowdhury, D.; Fahim N. A \& Salah Uddin M. (2012b). Action Regulation as Predictor of High Performance in Cricket. Shodh Sangam, January Special Issue, pp 211-15.

Saha Srilekha; Saha, S., Krasilschikov O., Ismail, M. S. (2012c). Predictive Structural Analysis in explaining Reaction Ability as a Mediator for Performance Excellence in Malaysian Athletes. Akash, pp 105-113.

Saha Srilekha, Saha, S., Krasilschikov O., Ismail, M. S. (2013d). Cognitive-emotional predictors of anticipation and reaction ability as mediator for performance excellence in south-asian athletes, Procedia Social and Behavioral Sciences. 91, pp $624-631$.

Saha, S.; Saha Srilekha; Mazlan, M. A. B. M. and Arriffin, M. I. B. M. (2013b). Effect of emotional regulation on performance of soccer skills, Procedia Social and Behavioral Sciences. 91, pp $594-605$.

Sequeira, H. and Roy J. C. (1993). Cortical and Hypothalamo-limbic control of electrodermal responses. In Roy et al. (1993a), pp. 93 -114.

Singer, R. N. (1988). Psychological testing: What value to coaches and athletes? International Journal of Sports Psychology, 19, pp 87-106.

Tenenbaum, G., Levi-Kolker, N., Bar-Eli, M. \& Sade, S (1992). Psychological selection of young talented children for sport. [Book Analytic] In Proceedings of the International Conference on Computer Applications in Sport and Physical Education, January 2-6, 1992, (Netanya), The E.Gill Publ. House : Wingate Institute for P. E. and Sport : The Zinman College of P. E., pp 268- 274.

\section{ACKNOWLEDGEMENT}

Dr. Soumendra Saha was supported by a Ministry of Higher Education research Grant (KPT Sport Research Grant - Perincian Geran Penyelidikan Tajaan Agensi Luar - KPT (Bhg. Sukan) (304/PPSK/6150128/K134). Authors of the present study are indebted to the Grant Authorities for having awarded to carry out the study. 